\title{
Stability of chromium compounds immobilized on organo-zeolites
}

\author{
T. BAJDA ${ }^{1 *}$, M. SOBCZYK ${ }^{1}$
}

${ }^{1}$ AGH University of Science and Technology in Krakow, al. A. Mickiewicza 30, 30-059 Krakow
(*correspondence:bajda@agh.edu.pl)

Surfactant-modified minerals are widely used for the sorption of anionic forms of contaminants, including chromium compounds. The growing emphasis on environmental protection and economic aspects leads to increased interest in the possibility of regeneration and reuse of the sorbent. The paper attempts to determine the regeneration potential of the synthesized organo-zeolites after the sorption of $\mathrm{Cr}(\mathrm{III})$ and $\mathrm{Cr}(\mathrm{VI})$ by conducting cycles of sorption-desorption of chromium using desorbing solutions. Hexadecyltrimethylammonium bromide (HDTMA) was used to modify the synthetic zeolite $\mathrm{Na}-\mathrm{P} 1$ and $\mathrm{Na}-\mathrm{X}$ derived from fly-ash, obtaining a surface coverage of 1.0 external cationexchange capacity (ECEC). Several desorbing solutions were used, such as $\mathrm{KOH}, \mathrm{KNO}_{3}, \mathrm{Na}_{2} \mathrm{CO}_{3}, \mathrm{~K}_{2} \mathrm{HPO}_{4}, \mathrm{NaHCO}_{3}$, $\mathrm{NaCl}, \mathrm{CH}_{3} \mathrm{COONa}, \mathrm{K}_{2} \mathrm{SO}_{4}, \mathrm{Na}_{2} \mathrm{~S}_{2} \mathrm{O}_{4}$. During the five sorption-desorption cycles, the ability to $\mathrm{Cr}(\mathrm{III})$ and $\mathrm{Cr}(\mathrm{VI})$ of used solutions desorption decreased with the simultaneous activation of the sorbent, increasing its sorption capacity. The solutions showed similar properties and have different abilities to chromium desorption and the same of the sorbent regeneration potential. The reacted organo-zeolites were analyzed using X-ray diffraction (XRD), Fourier-transform infrared spectroscopy (FTIR), and scanning electron microscopy (SEM). The conducted experiments proved the possibility of effective regeneration of HDTMA-modified zeolites using desorbing solutions. Activation of the sorbent surface may be caused by the development of the sorbent surface under the influence of aggressive alkaline desorbing solutions, resulting in a higher number of active centers available for surfactant molecules, thus increasing the modified surface with high affinity to chromate ions.

This research was financed by the Foundation for Polish Science (FNP), Poland, Grant No. TEAM-NETPOIR.04.04.00-00-14E6/18-00. 